\title{
An Investigative Study for Smart Home Security: Issues, Challenges and Countermeasures
}

\author{
Sudhir Chitnis' ${ }^{1}$ Neha Deshpande ${ }^{2}$, Arvind Shaligram ${ }^{3}$ \\ ${ }^{1}$ Vishwakarma College of Arts, Commerce and Science, Pune, India \\ ${ }^{2}$ Abasaheb Garware College, Pune, India \\ ${ }^{3}$ Department of Electronics Science, Savitribai Phule Pune University, Pune, India \\ Email: surusudhir21@gmail.com
}

Received 3 March 2016; accepted 22 April 2016; published 25 April 2016

Copyright (C) 2016 by authors and Scientific Research Publishing Inc.

This work is licensed under the Creative Commons Attribution International License (CC BY). http://creativecommons.org/licenses/by/4.0/

(c) $\underset{\mathrm{EY}}{\mathrm{F}}$ Open Access

\section{Abstract}

Home security should be a top concern for everyone who owns or rents a home. Moreover, safe and secure residential space is the necessity of every individual as most of the family members are working. The home is left unattended for most of the day-time and home invasion crimes are at its peak as constantly monitoring of the home is difficult. Another reason for the need of home safety is specifically when the elderly person is alone or the kids are with baby-sitter and servant. Home security system i.e. HomeOS is thus applicable and desirable for resident's safety and convenience. This will be achieved by turning your home into a smart home by intelligent remote monitoring. Smart home comes into picture for the purpose of controlling and monitoring the home. It will give you peace of mind, as you can have a close watch and stay connected anytime, anywhere. But, is common man really concerned about home security? An investigative study was done by conducting a survey to get the inputs from different people from diverse backgrounds. The main motivation behind this survey was to make people aware of advanced HomeOS and analyze their need for security. This paper also studied the necessity of HomeOS investigative study in current situation where the home burglaries are rising at an exponential rate. In order to arrive at findings and conclusions, data were analyzed. The graphical method was employed to identify the relative significance of home security. From this analysis, we can infer that the cases of having kids and aged person at home or location of home contribute significantly to the need of advanced home security system. At the end, the proposed system model with its flow and the challenges faced while implementing home security systems are also discussed.

\section{Keywords}

Home0S, Smart Home, Intelligent Remote Monitoring, Graphical Method, Home Security System 


\section{Introduction}

The first thing you desire when you look at your family and your home is their safety. And thus the idea of advanced home security system comes into picture. The concept of home automation and its safety has been around since late 1970s. But during the course of time with the advancement of technology, our expectation from home has changed a lot and so have the idea of home automation and its security systems. If we look at different home automation systems over time, they have always tried to provide efficient, convenient and safe ways for home inhabitants to access their homes [1].

Although user's expectations have changed and technology is advanced but the role of a home security system has remained the same. And if your family members are safe and secure, you can live in tranquility. But is this really happening in current scenario where the crime rates are ever rising? Most of us often overlook and ignore the importance of home security. The Metropolitan Police Service (MPS) takes burglary very seriously. We understand that it can be both financially costly and emotionally devastating for victims and their families [2]. Proper timely precautions can save you with all such consequences. And installing a smart security system and turning your home into smart home can be the solution to all these problems; providing such security system is hassle-free and user-friendly. Smart home can be also known as automated home or intelligent home which indicates the automation of daily tasks with electrical appliances used in homes [3]. By intelligent remote monitoring, the user can have remote access to the home. And in case if any trespasser tries to enter the home, the user will be immediately intimated with this unusual activity by the system. These advanced home security systems will work as "Virtual Watch Guard" of your home. It has many advantages; e.g., it will protect your home from trespasser, help you to monitor your home remotely. You can also keep watch on kids or elderly people left at home which gives the sense of security and peace of mind. This feeling of having a safe home will itself help you to be more productive and focused.

You might live in a reliable and sound neighborhood, but crime happens everywhere. Criminals might try to break into your home but having a predefined plan in place will protect your family members and personal property. Such plan is very essential to your security. It is essential to make sure that everyone in your family knows the correct safety measures and also knows how to enable and disable any safety features or alarms in your home. Thus putting together a safety plan at home will keep each one on the same page.

To do an investigative study for home security, we conducted a survey of various people from different backgrounds like people living in urban, suburban or rural areas, working or non-working people, and the ones who stay in different types of accommodations like a flat, row home or a villa. In this survey, we also considered people who have kids staying at home and/or aged parents who wish to live independently. Then an evaluation of currently installed security system is done and using that we have tried to find out different security measures adopted by the users. At the end of this survey we will also try to find out their opinion about advanced security system.

Our main aim is to develop a socially intelligent robot (SIR) which will classify and recognize the human robot interaction (HRI) in real time for the smart home system and enhance the home security to next level. Section 2 described objectives and review of home security model. Section 3 explained the need of HomeOS Investigative study. Section 4 described the intention behind investigative study and graphical method which was employed. Section 5 presented the results obtained and the discussions on the result. Section 6 provided the brief idea of proposed system model and its flow. Section 7 described the challenges faced in home automation security and Section 8 concluded the paper.

\section{Objectives and Home Security Model Review}

\subsection{Objectives}

Our work focuses mainly on the security aspect of home automation. Specifically, here we can state the objectives as follows:

- To review the existing home security systems by conducting survey and analyzing the results of the same by graphical method.

- An evaluation of need of security of people from different backgrounds based on different parameters like children and/or aged person staying at home, people living in rural or urban area etc. and finding the impact 
of these parameters on their need of home security systems.

- To examine the feasibility of installing advanced security system in rural and urban areas.

- To test the awareness of people for advanced security system.

- To establish the benefits of installing advanced security system.

- Development of possible future advanced home security systems using wireless sensor network and biometrics systems.

\subsection{Home Security Model Review}

There are many home security systems for intelligent remote monitoring and controlling, which are designed as business related products or under research programs for experiment. It is observed that most of the research carried out fits in the following categories:

1) Internet based Monitoring using Servers, GPRS modems, etc. with various approaches,

2) GSM-GPRS protocols using module individually or in combination with Internet Technologies,

3) Wireless Sensor Networks especially for Monitoring using Bluetooth, Wi-Fi, etc.

4) Biometric has various wide range applications like Home Automation, Home Security Systems, Biomedical Applications, Health Monitoring, Agriculture, etc.

Alheraish [4] in 2004 presents a design and implementation of remote control system by means of GSM cellular communication network and implemented home security system using microcontroller and Sony Ericsson GM-47 GSM module. In this paper, two home applications are experimentally tested using PC-based environment and verified the principle operation of the M2M design and also provides password facility for key based door lock and control home lighting system.

Van Der Werff et al. [5] proposed a mobile-based home automation system that consists of a cellular modem, a home server and most importantly mobile phone with Java capabilities. Here, the home server controls the home appliances via the cellular modem. In the proposed system, the home server is built upon a SMS/GPRS mobile module Sony Ericsson and a microcontroller Atmel AVR-169.

Khiyal et al. [6] work firstly tried to understand the voice of user then to control the home appliances through voice call and lastly to find out intrusion in the house. They also provided security and proposed SMS based system for controlling of home appliances remotely when the user is away from the place. The GSM Modem used in this paper allows to send and receive SMS to and from the system via RS232 serial port.

\section{Need of HomeOS Investigative Study}

According to the survey of Pune police in the city of Pune which is one of the fastest growing cities in India, in the year 2015 alone, there had been 1200 cases of home burglaries in which only 240 cases were solved. Such burglaries amounted to loss property worth Rupees 15 crore and 72 lakhs out of which only valuables worth rupees 2 crore has been recovered. Frequency of such burglaries is found to be more in the suburban areas of Pune but even in the heart of the city such incidences are happening. Most of the people in Pune stay in flats and thus they are not much informed about their neighborhood. The criminals take advantage of such situation. The Pune police suggest that, every responsible citizen should take some precautionary steps to avoid the home burglaries. If one is going out of station the neighbor should be informed about the same. All the valuables should be kept at a safe space like bank lockers. The security guards should be appointed only after the strict scrutiny from the police from respective area. Society should be protected by CCTV cameras or likewise any advanced home security systems. When it comes to home burglaries even the small precautions matter, for example telling the newspaper vendor to stop giving the daily newspaper when one is out of station as the heap of newspaper will signal the criminals that house is locked for many days [7].

If we consider above cases, then the first question which comes to our mind 'Is our home really secure?' We start to think whether the security measures we have taken are enough. By placing an appropriate home security system one can protect their home from criminals. Nowadays, safety depends on how well trained you are and how well secured you are. Of course, you can empower yourself and give yourself as well as your family peace of mind with monitored biometric residential security systems. But, the main question arises is that are you aware of such system? If yes, is it affordable to you and is it available easily in market and is it feasible enough to install, operate and maintain. To find the answer of all these questions, we have done an investigative study. 
A home security survey or investigative study is a serious on-sight assessment of a property to determine what the present security status is and to find out any scarcities or excesses of security. It determines the level of protection needed and give suggestions to improve the overall security of your home, if required. Traditional techniques of alarm based security have gained much popularity in past decades. Nowadays, embedded system is designed to provide security due to tremendous improvement in microcontroller unit and widespread applications of GSM technology [8]. Most of our homes are still protected by simple lock-and-key mechanisms. Nowadays, most of the families are of nuclear type where almost all adults are working professionals. And as a result the children at home are left unattended or in the company of servant or a babysitter who are not trustworthy most of the times. Thus, relying on traditional lock-and-key security mechanism is rather risky. Generally, robbery or crimes are committed by low skilled criminals. They use tools such as crowbars, channel lock pliers, etc. to gain entry. Due to the inadequate security of many premises, these relatively unskilled people can gain entry in 4 to 45 seconds [9]. This investigative study is intended to reduce the likelihood of your home being targeted by criminals and make you aware of your concern of home safety. Although there are no foolproof methods for preventing robbery, but it gives you an idea about monitoring your home, especially when the kids and/or elderly persons are alone or with servant or babysitter, etc.

\section{Intention behind Investigative Study and Method Employed}

The primary goal of investigative study was to create awareness regarding the safety measures one can take in day-to-day life. And the secondary goal was to emphasize on requirement of advanced home security system which will make your home more crime resistant. To collect the data from users a questionnaire consisting of 20 questions evaluating various aspects of home security was provided. The intention behind administering this questionnaire was to provide the resident to take a review of his/her home's safety. As the respondents finish this survey, they will assess it against their personal lifestyle and according to the security upgrading they choose to make.

First question was the basic and most necessary one. In this question the respondents were asked to evaluate or rate their existing home security system. Next group of questions collected and evaluated other information like the location and type of the home, number of entrance points to the house etc. Most of the people were from suburban area living in a flat with single entrance. We also evaluated the working status of the respondent and his/her family member. Here we can see that irrespective of urban or rural area, most of the family members are working. Next section of questionnaire comprised of the questions related to neighbors where respondents were asked whether they trust their neighbor or not, the kind of supervision their kids/aged person is having at home, general safety precautions like availability of locker, emergency contact number and the type of current security systems installed. In last section of the survey, we were interested to know that whether they are thinking of installing any highly advanced security system and do they feel that one-time-investment in a smart and intelligent security system is beneficial.

The population of the study constituted of people residing in urban or rural areas and of either working or non-working background. Each person was requested to fill a questionnaire which was based on various issues of home security and on the factors that affect home security. No restrictions of time were imposed on the respondents. Graphical method was used to analyze the findings of the survey.

\section{Graphical Method}

In this analysis, each response was evaluated by doing coding and all the responses were tabulated and analyzed in a graphical format as shown in Figure 1.

In above Pie-diagram, it is observed that, 67 out of 78 studied cases i.e. $86 \%$ of the people who took the survey are of the opinion that their home is somewhat secure and the rest i.e. only $14 \%$ are satisfied with their current home security.

When asked about the kind of security system installed in their home, 97\% people still have traditional lock-and-key system which is shown in Figure 2.

And most importantly, out of 78 studied cases of different types as mentioned previously, 74 i.e. near about $95 \%$ users think that, one-time investment in smart and intelligent security system is worth to eliminate the cons involved in the traditional security system, which is shown in Figure 3. 


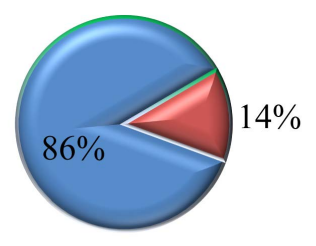

四 Not very secure

Figure 1. Pie-chart: opinion about existing home security system in percentage.



口Lock-and-Key $\quad$ CCTV+Lock

Figure 2. Pie-chart: representations of existing home security system.

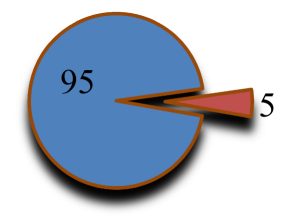

$\square$ Worth of investment in advanced Security system (\%)

- Not necessary (\%)

Figure 3. Pie-chart showing \% of people in favor of advanced smart security system.

\section{Results and Discussion}

First of all a questionnaire constituting of 20 questions related to home security was administered to people of diverse backgrounds and then applying graphical method representation yields into following results:

1) Out of all the people who took the survey, $58.57 \%$ have some or the other type of adult supervision and other i.e. $41.43 \%$ don't have any type of adult supervision for their children who are at home when they leave for their work.

Now out of all the children who are left at home $58.54 \%$ get the supervision of their grandparents, $36.59 \%$ are left in the custody of the babysitters and the others i.e. 18.18\% get some other kind of supervision. As indicated in graph, working parents are always worried about their children and they feel that advanced security system can give them peace of mind.

2) One of the important observations of this survey was that out of total 78 people $97.44 \%$ of them still has a traditional lock-and-key system at their home and only $2.56 \%$ are aware of advanced security mechanism. These figures brought to our notice that not many people are aware of advanced security system. Criminals always look for easy targets, and by taking appropriate precaution you can drastically decrease the chances of having your home victimized.

3) People who live in urban or suburban area are in need of more security than the people who live in rural areas.

4) The investigative study thus arrived at the conclusion that $95 \%$ of the respondents are thinking that advanced security system is the need of the hour and will definitely be advantageous to achieve the contentment. 
In other words, one-time investment in smart security system is significant to reduce the cons involved in the traditional lock-and-key security system.

The remaining 5\% who are not in favor of advanced security system are from rural area. Their responses showed that they are not eager to install the same although some of them are aware of the system. The reasons behind this are the overall traditional atmosphere of rural areas, the culture of joint family and the mutual trust between the families in the premises where they can rely on each other for general security reasons. Also, in rural areas mostly the entrance points are more than one and hence installing advanced security system at every such point will not be feasible.

As $95 \%$ of people are in favor of advanced security system, such system can be accomplished using various technologies like wireless sensor network and biometrics etc.

\section{Proposed System Flow}

At the time of purchasing, people are normally looking for no-stress, no-hassle and straightforward home security system along with quick and easy installation, crash and smash protection, great value for money, no landline or broadband options, if they are in rural area with advanced full-proof technology and equipment warranty.

The jobs of a modern home security system include identifying an intruder trying to gain access, alerting the homeowner, preventing the intruder and collecting evidence regarding the intrusion.

By considering all above points, we would like to propose our home security system as follows:

Initially, our proposed system will capture the biometric of the user for creating first hand database. At the time of entry, this input biometric database will be further accessed by the system for authentication purpose. Then, the database image and the current biometric input image will be matched to give the authorization to the user. If the current input image is the true copy of the database, then the system will respond to the user and give access.

Or for hassle free or easy access the user will give a response by executing an application from his/her Smartphone. Then the input from the application will be taken by the system for comparison with the database. Here, system will give an authentication to the user, if and only if the biometric image and input from the application are matched. Otherwise, the system will send a message to the owner of the home so that the owner can take an appropriate action against the un-authorized person, who is trying to get access to the home.

Note that, to add a new user at any time, owner reserves all rights. The guests or friend can get access to the main door using Smartphone via Bluetooth and/or biometrics, if that person is added in the list of authentic users by the owner. The door will be set to open automatically, when the owner is in the proximity. Invitations can be sent to family, friends, guests or a handyman and record their database templates so they can enter the home without the owner being actually present in the home. Time slots and limits can be added to this invitations ranging from one hour to "always" and most importantly, can be cancelled at any time.

You can also incorporate distinct levels of security inside the home. Level 0 can give one access to a new person till the main hall of the home. Level 1 access can be granted to people like handyman, plumber etc so that they can go up to say washrooms or likewise. The babysitter or maids or servant who have to work in kitchen, guest room or dining hall can have right of entry under level 2. System can detect if someone tries to violate the prescribed levels. When a person enters the home, the level under which s/he has entered is activated and if s/he crosses the boundary stated in the respective level then immediately the system will sense the unwanted movement and alert the owner about the same.

Figure 4 shows flow chart of the proposed system.

Above proposed model may give proper expected response using intelligent remote monitoring and definitely will prove to be effective and applicable in real time.

\section{Challenges Faced in Home Automation Security}

In this section, we discuss various challenges faced by home automation systems as these systems are an attractive target for an attacker. A homeowner or the system administrator may not be eager to do the necessary upgrades required to keep the system working properly is the main concern. Also, home security and automation system are assembled using the different devices from different manufacturers which make it susceptible to failures. Mostly, home owner who is not an expert in advanced technology may try to reconfigure the system which 


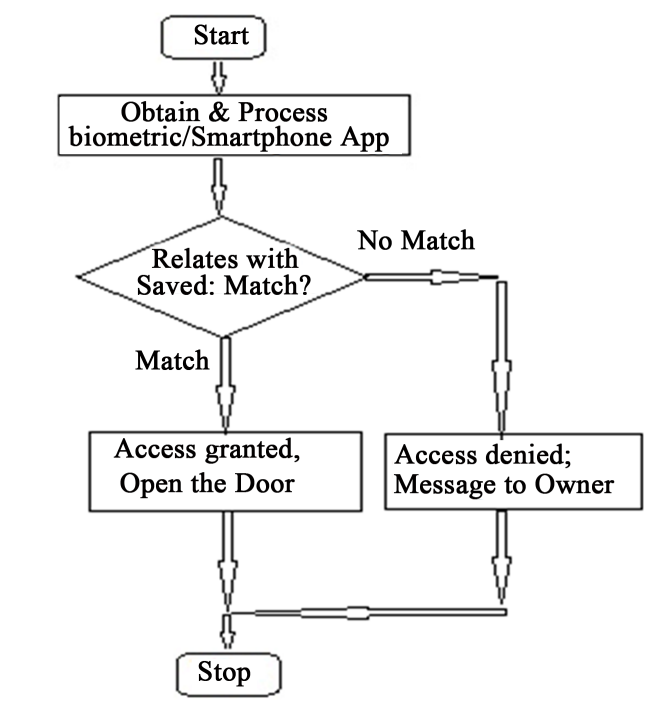

Figure 4. Flow chart of the proposed system.

may result in complete failure of system. And, the most important thing is that, average customer normally consider the cost of purchasing and installing such system. As a result of it, they may purchase an inappropriate system owing to their unawareness, misinformation or lack of interest towards various security issues. Another important hurdle is that, all guests can't be expected to be careful about security and may also feel insulted if the home entry is restricted to them at some point. Similarly, senior citizen's limited technological knowledge may be a major hindrance.

Smart home's round-the-clock internet connectivity makes it vulnerable to an attack which can be carried out from any corner in the world. If a system is compromised, it may cause huge scale damage both emotional and financial.

\section{Conclusion}

Our work mainly concentrates on security aspect of the existing home automation system and also points out its drawbacks. It explains the concept of security and actual meaning of the word "intruder" in modern times. The paper highlights the shortcomings of existing home automation systems faced in identifying and preventing the sophisticated intruders from breaking into home. We encourage the researchers to consider a home automation system as one of the most important parts of home security and develop advanced sensing technology to identify and protect the homes from skilled intruders. Security factor is most important when it comes to proper implementation and development of automated home security systems. Such system will definitely provide a sense of security to every person at home and will also put their mind at ease.

\section{References}

[1] Cyril Jose, A. and Malekian, R. (2015) Smart Home Automation Security: A Literature Review. Smart Computing Re view, 5, 269-285.

[2] Metropolitan Police. Advice on Burglary Prevention, 1-26. http://www.met.police.uk/crimeprevention/docs/bumblebee_burglary_prevention.pdf

[3] Bangali, J. and Shaligram, A. (2013) Design and Implementation of Security Systems for Smart Home Based on GSM Technology. International Journal of Smart Home, 7, 201-208. http://dx.doi.org/10.14257/ijsh.2013.7.6.19

[4] Alheraish, A. (2004) Design and Implementation of Home Automation System. IEEE Transactions on Consumer Electronics, 50, 1087-1092. http://dx.doi.org/10.1109/TCE.2004.1362503

[5] Van Der Werff, M., Gui, X. and Xu, W.L. (2005) A Mobile-Based Home Automation System. 2nd International Conference on Mobile Technology, Applications and Systems, Guangzhou, 15-17 November 2005, 1-5. http://dx.doi.org/10.1109/mtas.2005.207158

[6] Butt, M., Khanam, M., Khan, A. and Sikandar Hayat Khiyal, M. Controlling Home Appliances Remotely through 
Voice Command. International Journal of Advanced Computer Science and Applications, Special Issue on Wireless and Mobile Networks, 35-39. www.ijacsa.thesai.org

[7] Kolhe, S. (2016) Average of Robbery Cases in Pune City: Three per Day. (English Translation of Marathi News) Maharashtra Times Marathi Newspaper, 24 February 2016, 1-2.

[8] Hasan, R., Khan, M.M., Ashek, A. and Rumpa, D. (2015) Microcontroller Based Home Security System with GSM Technology. Open Journal of Safety Science and Technology, 5, 55-62. http://dx.doi.org/10.4236/ojsst.2015.52007

[9] Tucson Police Department. Home Security Survey-Improve the Safety of Your Home. Home Security Booklet. 